\title{
Phosphorus Speciation in Municipal Wastewater Solids and Implications for Phosphorus Recovery
}

\author{
Felipe Gutierrez, ${ }^{1,2, *}$ Kerry A. Kinney, and Lynn E. Katz ${ }^{1, \dagger}$ \\ ${ }^{1}$ Civil, Architectural and Environmental Engineering Department, The University of Texas at Austin, Austin, Texas. \\ ${ }^{2} \mathrm{CP} \& Y$, Inc., San Antonio, Texas.
}

Received: August 30, 2019 Accepted in revised form: January 23, 2020

\begin{abstract}
The most popular method for recovering phosphorus from municipal wastewater solids is precipitation of dissolved phosphate (e.g., Struvite). New technologies are being developed to recover particulate phosphorus that are not typically recovered. However, to identify the optimum recovery technology for a given wastewater solids stream, the speciation and concentration of phosphorus within the solids must first be determined for conventional wastewater treatment plants as well as those with enhanced phosphorus recovery. To this end, the present study: (1) examined the potential for phosphorus recovery as a function of the type of wastewater treatment plant process and $\mathrm{P}$ recovery technology; (2) assessed the potential for improving $\mathrm{N}: \mathrm{P}_{2} \mathrm{O}_{5}$ ratios in the spent dewatered biosolids after phosphorus recovery and (3) determined the effects of solid treatment processes on phosphorus speciation in municipal wastewater solids. The results of the study indicate that the selection of technologies for P recovery should consider the type of wastewater treatment process and phosphorus speciation present. Finally, the current analysis suggests that only enhanced technologies that target particulate phosphorus phases have the potential to improve $\mathrm{N}: \mathrm{P}_{2} \mathrm{O}_{5}$ in the spent biosolids.
\end{abstract}

Keywords: municipal biosolids; municipal sludge; phosphorus recovery; phosphorus speciation; struvite

\section{Introduction}

Aedimentary apatite rock (also known as phosphate rock) is the main source of phosphorus supplying the world's fertilizer industry. Phosphate rock is mined from sedimentary deposits that are finite (Withers et al., 2015; George et al., 2016) and nonrenewable. Some estimates suggest that these deposits will be exhausted by the end of the century (Cordell et al., 2009). Moreover, the narrow geographic availability of these deposits could become a significant political issue in the near future. Thus, it is important to investigate and develop renewable sources of phosphorus.

Wastewater treatment plant solids are a promising source for phosphorus. It is estimated that $\sim 16 \%$ of the phosphorus mined annually is consumed by humans and ultimately ends up in wastewater (Cordell et al., 2009; Rittmann et al., 2011; Mayer et al., 2016). Depending on the wastewater treatment processes in place, between $20 \%$ and $90 \%$ of the phosphorus in wastewater can be removed and incorporated into the wastewater solids (Barnard, 1984; Dueñas et al., 2003; Brunner, 2010; Mayer et al., 2016). This amounts to approximately 0.6-2.9

*Corresponding author: CP\&Y, Inc., 12500 San Pedro Avenue No. 450, San Antonio, TX 78216, USA. Phone: 512-740-9176; Fax: 210-494-8286; E-mail: felipe_gutierrez@utexas.edu

${ }^{\dagger}$ Member of AEESP. million metric tons of phosphorus a year available for recovery (Cordell et al., 2009). Unfortunately, current technologies for phosphorus recovery are far from achieving $100 \%$ efficient recovery or reuse of the phosphorus in wastewater solids.

The most widely available method for phosphorus recovery is struvite precipitation of dissolved phosphate (e.g., Ostara Pearl, PRISA, Phostrip, AIRPREX ${ }^{\mathrm{TM}}$ and others) (Coats et al., 2011; Sartorius et al., 2012). The major drawback of technologies that recover phosphate from solution is that the phosphorus present in the particulate phase of the solids cannot be recovered. Cullen et al. (2013) reported that over $73 \%$ of the total phosphorus in wastewater solids cannot be recovered using struvite precipitation technology. To address this issue, new technologies have been developed to recover phosphorus from the particulate phase in wastewater solids. The Stuttgart Process targets particulate species by decreasing the $\mathrm{pH}$ in the sludge with sulfuric acid, before dewatering. $60-67 \%$ of the total phosphorus in the wastewater solids can be recovered as struvite through this method (Table 1) (Güney et al., 2008; Antakyali et al., 2013). The KREPRO process targets total condensed polyphosphates and total orthophosphates by acidification and pressure heating the solids. Researchers have reported that between $60 \%$ and $75 \%$ of the total phosphorus in the wastewater solids can be recovered with this technology (Hultman, 1999; Karlsson and Kemira, 2001; Sengupta et al., 2015). 
Table 1. Phosphorus Recovery Estimates Reported in the Published Literature FOR THE AIRPREX, StutTgart, AND KREPRO TECHNOLOGIES

\begin{tabular}{|c|c|c|c|}
\hline $\begin{array}{l}P \text { recovery } \\
\text { technology }\end{array}$ & $\begin{array}{l}\text { Recovery from } \\
\text { biosolids (\%) }\end{array}$ & $\begin{array}{l}\text { Type of } P \\
\text { removal at } W W T P\end{array}$ & References \\
\hline AIRPREX $^{\mathrm{TM}}$ & 86-98\% DP & EBPR & Stumpf et al. (2009); Nieminen (2010) \\
\hline Stuttgart Process & $60-67 \%$ ТP & Chem-P & Güney et al. (2008); Antakyali et al. (2013) \\
\hline KREPRO & $60-75 \%$ ТP & EBPR with Chem-P & Hultman (1999); Karlsson and Kemira (2001) \\
\hline
\end{tabular}

Chem-P, chemical phosphorus removal; DP, dissolved phosphate; EBPR, enhanced biological phosphorus removal; TP, total phosphate.

When evaluating phosphorus recovery technologies, the speciation and concentration of phosphorus present in both the liquid and particulate phases of wastewater solids are important parameters to consider. Most studies to date have not considered or reported these data when investigating the recovery of phosphorus. Also, the transformation of phosphorus from one form to another within wastewater solid streams (e.g., dissolved to particulate phosphorus) as a result of gravity thickeners and anaerobic digesters has not been thoroughly investigated. Furthermore, studies to date have focused primarily on the recovery of phosphorus from wastewater solids at plants that incorporate either biological (enhanced biological phosphorus removal [EBPR]) or chemical phosphorus removal (Chem-P) (e.g., Hansen et al., 2000; Kuroda et al., 2002; Güney et al., 2008; Petzet and Cornel, 2009; Marti et al., 2010; Rittmann et al., 2011; Cullen et al., 2013). Studies investigating $\mathrm{P}$ recovery in wastewater solids generated in conventional activated sludge (AS) plants are absent from the published literature despite the fact that conventional AS is the most common form of secondary treatment in the United States (EPA, 2016). This will likely continue to be the case since discharge standards are regulated by individual states and the motivation for implementing or not implementing total phosphate (TP) limits are diverse.

Finally, another factor that should be considered when evaluating phosphorus recovery from wastewater treatment plants is the nitrogen to phosphorus ratios $\left(\mathrm{N}: \mathrm{P}_{2} \mathrm{O}_{5}-\right.$ mass basis) in the spent dewatered biosolids after phosphorus recovery. A major disadvantage of direct land application of biosolids is the low nitrogen to phosphorus ratio present in biosolids (Korboulewsky et al., 1989; Yuan et al., 2012; Shaw et al., 2014). The ideal $\mathrm{N}: \mathrm{P}_{2} \mathrm{O}_{5}$ ratio for plant growth should be between 3 and 5 , but biosolids have a $\mathrm{N}: \mathrm{P}_{2} \mathrm{O}_{5}$ closer to 1 or less (Maguire et al., 2001; Chinault and O'Connor, 2008; Yuan et al., 2012). Thus, it is essential to understand how the $\mathrm{N}: \mathrm{P}_{2} \mathrm{O}_{5}$ ratio in biosolids is affected by phosphorus recovery technologies given that land application of biosolids with high phosphorus concentrations can lead to an over accumulation of phosphorus in the soil and make land application of wastewater solids unsustainable.

The overall objective of the current study was to measure phosphorus in wastewater biosolids from a range of different wastewater treatment plants to assess the potential for phosphorus recovery as a function of treatment process and recovery technology. To this end, the speciation and concentration of phosphorus present in wastewater solids and dewatering supernatants collected from nine wastewater treatment plants (including AS, EBPR, and Chem-P facilities) were determined. The data were used to estimate the potential recovery of phosphorus through the AIRPREX ${ }^{\mathrm{TM}}$, Stuttgart, and KREPRO technologies for each of the wastewater solid streams investigated as well as to estimate the nitrogen to phosphorus ratios ( $\mathrm{N}: \mathrm{P}_{2} \mathrm{O}_{5}$-mass basis) in the spent-dewatered biosolids after phosphorus recovery to evaluate their suitability for long-term land application. Finally, the effect of thickening and anaerobic digestion processes on phosphorus speciation was assessed.

\section{Materials and Methods}

\section{Wastewater treatment plants sampled}

Primary, secondary, thickened, and digested sludge as well as dewatered biosolids were collected from nine wastewater treatment plants in Texas. The treatment plants were given a code to maintain anonymity and were grouped by the type of phosphorus removal incorporated into each wastewater treatment plant (e.g., no targeted removal in conventional AS plants, chemical $\mathrm{P}$ removal through aluminum or ferric precipitation plants [Chem-P] or EBPR plants).

The flow diagrams for the first five wastewater treatment plants are shown in Fig. 1. AS1 through 5 (Fig. 1A-D) do not have any type of phosphorus removal in place. AS2 through 4 treat their wastewater solids onsite and dispose through land application. AS1 does not process their solids on site. Plant AS5 (Fig. 1E) is a solids-only treatment facility. Plant AS2 (Fig. 1B) operates two different types of thickeners, dissolved air flotation (DAF) for secondary sludge and gravity thickeners for primary sludge. AS3 does not have primary clarifiers; thus, their solids are composed of waste activated sludge (WAS) only. AS4 mixes both primary and secondary sludge before gravity thickening. The thickened solids are anaerobically digested and then dewatered for direct land application.

Treatment plant Chem-P1 (Fig. 2A) produces both primary and secondary sludge from a biological nitrogen removal process that is coupled with chemical phosphorus removal (precipitation with ferric chloride). Chem-P2 (Fig. 2B) only produces secondary sludge from biological nitrogen removal coupled with chemical phosphorus removal. Chem-P2 uses both ferric chloride and aluminum sulfate for phosphorus precipitation.

EBPR1 produces sludge from primary clarification and from an EBPR process. The wasted sludge is thickened, digested, and disposed through land application. Meanwhile, EBPR2 only produces secondary sludge from a biological phosphorus removal process. The wasted solids are thickened by rotary drum thickening and then stored inside a steel container. Every day the container is emptied into a cistern truck and the solids are hauled to a solid's processing facility. 
A

FIG. 1. Flow diagrams for the conventional AS wastewater treatment plants sampled in this study: (A) AS1, (B) AS2, (C) AS3, (D) AS4, (E) AS5. AS, activated sludge. Further detail is provided in Supplementary Table S1.

C
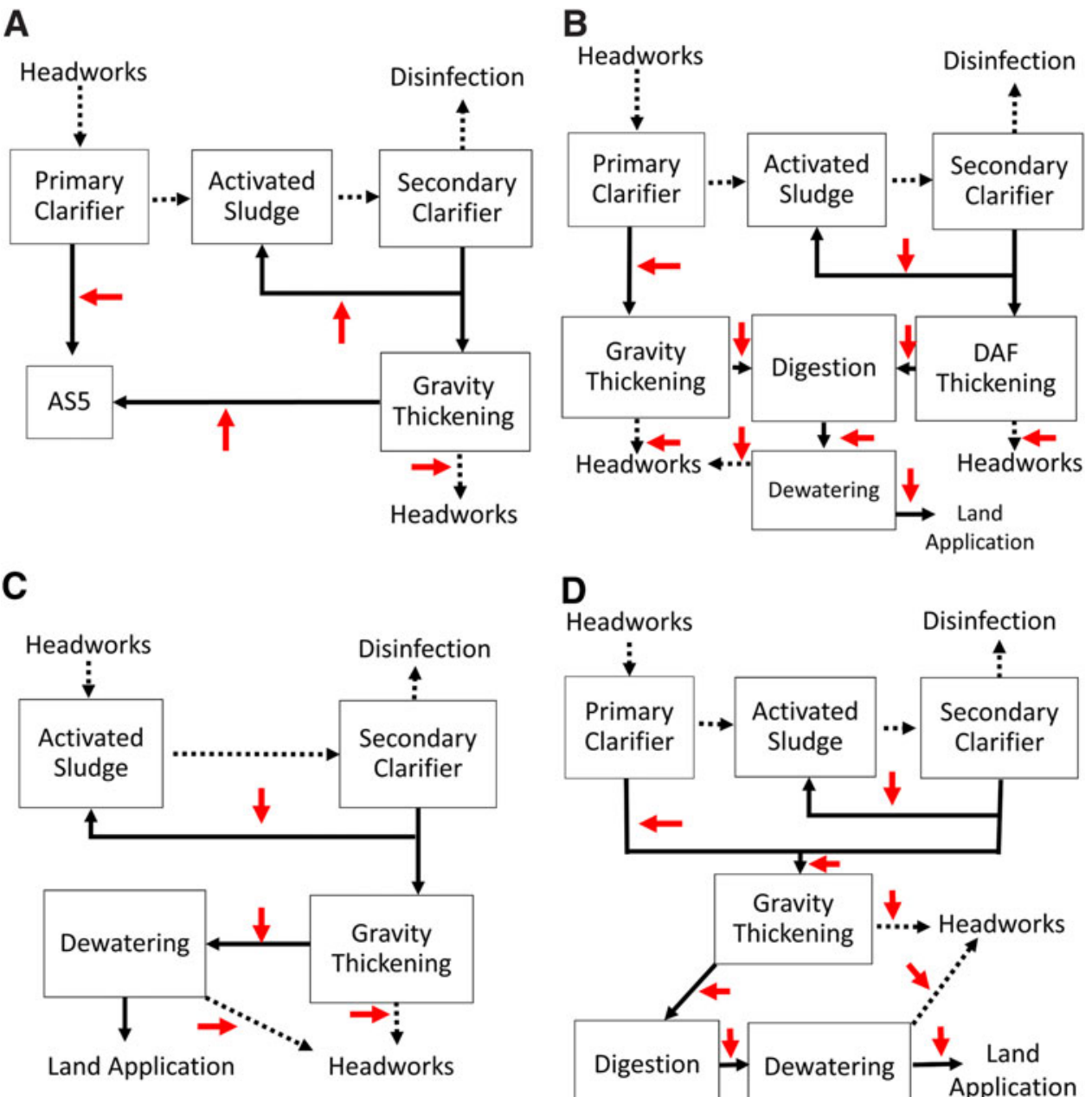

D

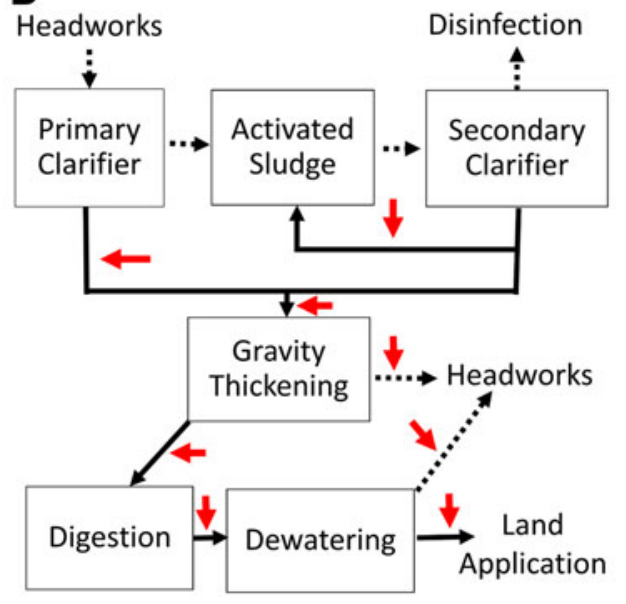

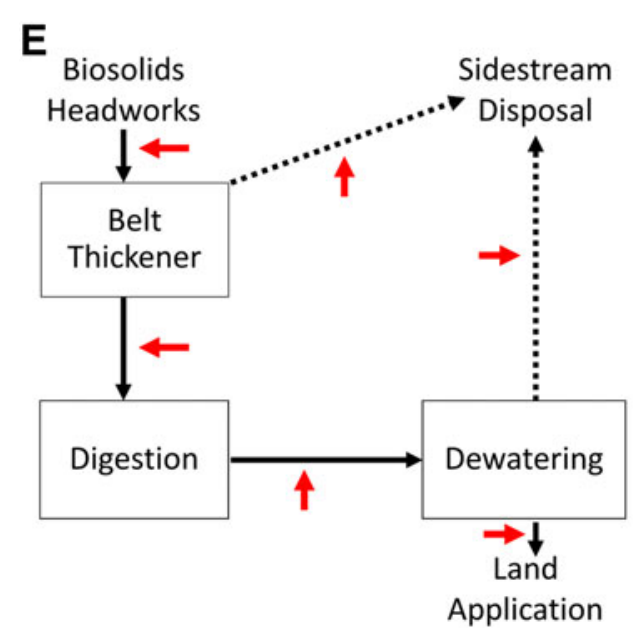

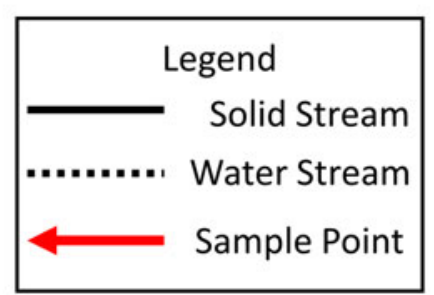

For reference, the influent characteristics (Biological Oxygen Demand, Total Suspended Solids, Ammonia, Dissolved Orthophosphate) for all the wastewater treatment plants are provided in Supplementary Tables S1 and S2.

\section{Sampling regime}

Influent and effluent samples were collected from each unit process shown in Figs. 1 and 2 over 3 consecutive days. The samples were collected in 250-mL acid-washed HDPE bottles. The samples were immediately refrigerated after collection.

\section{Phosphorus analysis}

Before analysis, samples were filtered through $0.45 \mu \mathrm{m}$ filter paper (reinforced cellulose Millipore RW03; Millipore Corp., Billerica, MA). The filtrate was used to determine the 
A
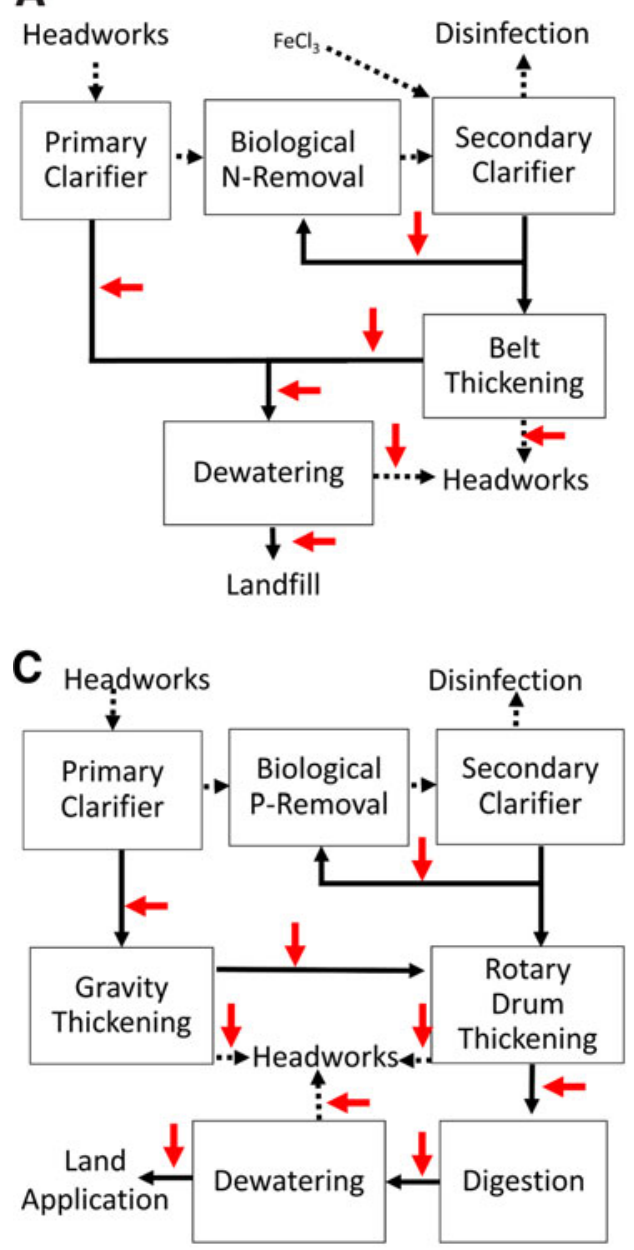

B
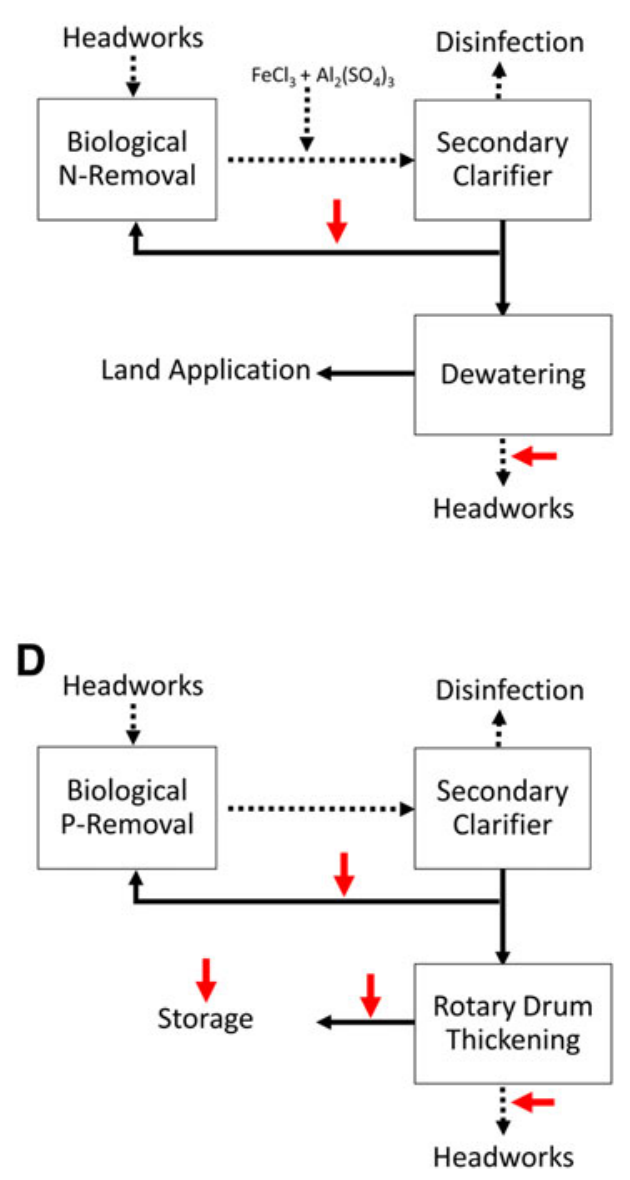

FIG. 2. Flow diagrams for the wastewater treatment plants with chemical phosphorus removal [(A) ChemP1 and (B) Chem-P2] and biological phosphorus removal [(C) EBPR1 and (D) EBPR2]. Chem-P, chemical phosphorus removal; EBPR, enhanced biological phosphorus removal. Further detail is provided in Supplementary Table S1.

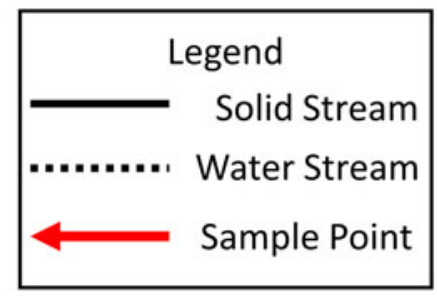

dissolved phosphorus species (liquid phase) and the unfiltered sample was used for determining total phosphorus species (liquid and solid phases). The particulate concentrations were determined indirectly by calculating the difference between the measured total and dissolved concentrations of each phosphorus species.

Phosphorus species are typically defined by the technique used to extract and analyze the phosphorus. One of the most common and standardized phosphorus speciation techniques (Standard Method 4500-P) separates and quantifies the orthophosphate, condensed polyphosphate, and organic phosphate constituents in a solid or liquid phase sample (APHA, 2012).

Orthophosphate was measured by colorimetry using the ascorbic acid method (APHA, 2012). Wastewater solid samples were acidified to $\mathrm{pH} 2$ using $11 \mathrm{~N} \mathrm{H}_{2} \mathrm{SO}_{4}$ before determination of total orthophosphate (dissolved+particulate) to dissolve all the particulate orthophosphates (Hultman,
1999; Hansen et al., 2000; Antakyali et al., 2013). Dissolved and total orthophosphate concentrations were measured immediately after sample collection.

To measure condensed poly and organic phosphates, acid hydrolyzable (ortho+condensed polyphosphates) and total (organic+condensed poly+ortho phosphates) phosphorus species had to be converted into orthophosphate. Acid hydrolyzable phosphorus was converted to orthophosphate by acid digestion with an $11 \mathrm{~N} \mathrm{H}_{2} \mathrm{SO}_{4} / 4 \mathrm{~mL} \mathrm{HNO}_{3}$ acid solution (APHA, 2012). Total phosphorus was converted to orthophosphate by persulfate digestion (APHA, 2012). This speciation method (APHA, 2012) was selected for use in the present study because it is a standard procedure to determine phosphorus in wastewater and wastewater solids (Münch and Barr, 2001; Dueñas et al., 2003; Pastor et al., 2008; Shimamura et al., 2008; Zeng et al., 2010). Moreover, the extraction methods are similar to the phosphorus recovery technologies being studied (Hansen et al., 2000; Güney et al., 2008; Sartorius et al., 2012; 
Antakyali et al., 2013). It is important to note that the condensed polyphosphates measured through Standard Methods 4500-P are not equivalent to the polyphosphates accumulated by polyphosphate-accumulating organisms (PAO-polyphosphates). PAO-polyphosphates are a subset within the condensed polyphosphate species that also include pyrophosphates, triphosphates, and metaphosphates (Greenfield and Clift, 1975; APHA, 2012).

\section{Calcium, potassium, and magnesium}

The dissolved concentrations of calcium, potassium, and magnesium were measured by inductively coupled plasma optical emission spectrometer (ICP-OES, Varian 710-ES) as described by EPA method 6010B (EPA, 1996).

\section{$\mathrm{pH}$, total, and volatile solids}

$\mathrm{pH}$ was determined using a double junction Cole-Parmer $\mathrm{pH}$ probe and an ORION 920A pH meter. Total and volatile solids were measured gravimetrically using a modified Standard Method 2540 B and 2540 E (APHA, 2012).

\section{Statistical methods}

The significance of the observed changes and differences in phosphorus speciation concentrations and in $\mathrm{N}: \mathrm{P}_{2} \mathrm{O}_{5}$ were evaluated using the Student's $t$-test.

\section{Results and Discussion}

The concentration and speciation of phosphorus in the wastewater solids and dewatering streams were measured across nine wastewater treatment plants. These data were combined with the technology performance data reported in the published literature for three phosphorus recovery technologies (AIRPREX $^{\mathrm{TM}}$, Stuttgart Process, and KREPRO) to estimate the potential for phosphorus recovery from conventional (AS), chemical $\mathrm{P}$ (Chem-P), and EBPR wastewater plants. To assess the suitability of the dewatered biosolids for land application after phosphorus recovery, the $\mathrm{N}: \mathrm{P}_{2} \mathrm{O}_{5}$ biosolid ratio resulting from each phosphorus recovery technology studied was also calculated. Finally, the phosphorus data collected from the wastewater treatment plants were used to determine how thickening and anaerobic digestion affect the concentration and speciation of phosphorus in wastewater solids as well as the potential for phosphorus recovery.

\section{Comparing phosphorus speciation in EBPR, Chem- $P$, and AS solids}

Figure 3 summarizes the phosphorus speciation within thickened solids (Fig. 3A) and digested solids (Fig. 3B) collected from the sampled waste water treatment plants (WWTPs). Substantial variability was observed in the $\mathrm{P}$ measurements even at plants of similar design (e.g., conventional AS systems). This result reflects the inherent differences in the design and operation of different wastewater treatment plants. This variability has also been observed and reported by other authors measuring phosphorus at full-scale wastewater treatment plants (Lawler and Singer, 1984; Szpyrkowicz, 1995; Dueñas et al., 2003; Danesh et al., 2008). Despite this inherent variability, however, significant trends were observed in the phosphorus speciation of municipal wastewater solids produced at the different types of wastewater treatment plants (AS, Chem-P, and EBPR). A twosided Student's $t$-test was performed to assess the significance of the observed differences and the results are presented in Supplementary Table S3. An expected observation is that the total phosphorus concentrations present in undigested EBPR $(30 \mathrm{mg} / \mathrm{g} \pm 12)$ and Chem-P solids $(29 \mathrm{mg} / \mathrm{g} \pm 5)$ were on average twice the levels measured in undigested conventional AS solids $(15 \mathrm{mg} / \mathrm{g} \pm 6)$. Additionally, undigested conventional AS solids contain slightly higher concentrations of dissolved orthophosphates compared with EBPR $(p<0.01)$ and Chem-P $(p<0.01)$ undigested solids. EBPR plants and chemical phosphorus removal plants are designed to incorporate the dissolved phosphorus present in raw wastewater into the particulate phase to be removed through sedimentation (Tchobanoglous et al., 2004). Therefore, higher total phosphorus concentrations and lower dissolved orthophosphate concentrations are expected in undigested solids from EBPR and Chem-P plants relative to the undigested solids generated at AS plants.
FIG. 3. Phosphorus speciation for (A) undigested solids and (B) digested solids in three different wastewater treatment plant types.

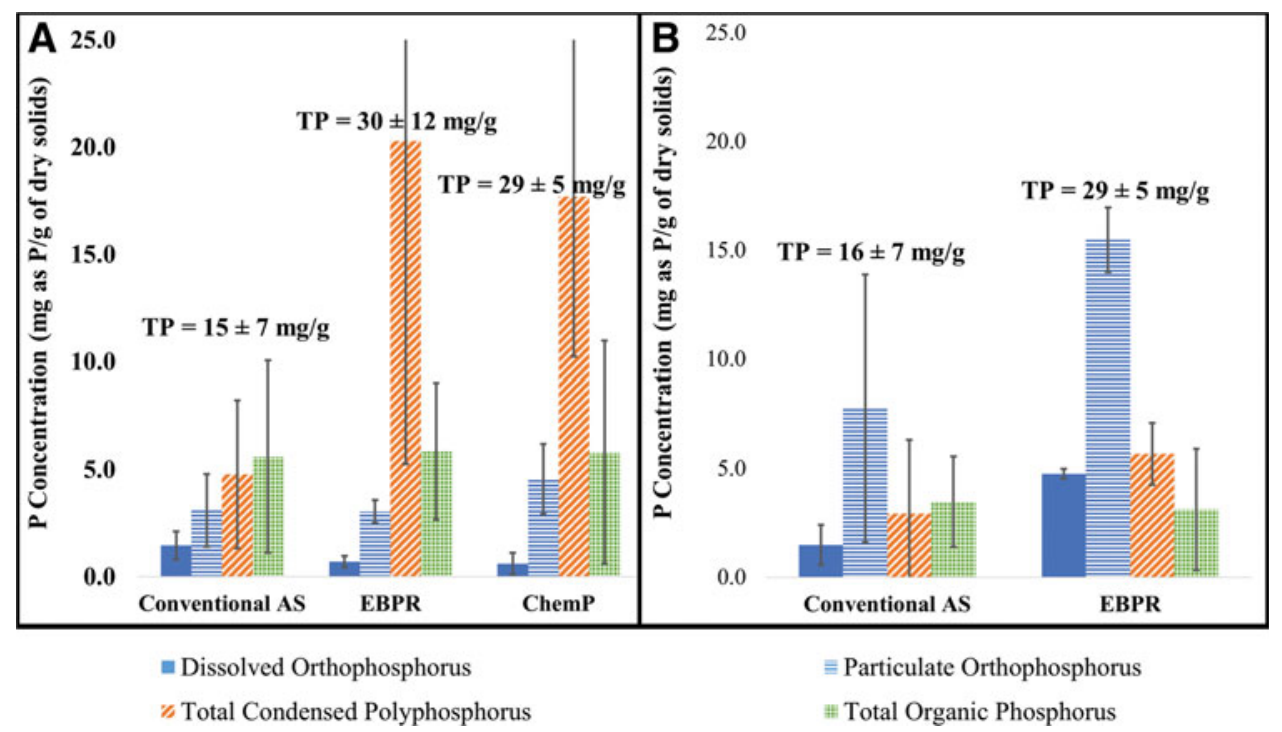


With respect to the particulate phase, undigested solids derived from wastewater plants with chemical phosphorus removal had a higher particulate orthophosphate concentration (although not statistically significant) compared with both EBPR $(p=0.07)$ and AS $(p=0.1)$. This is not surprising given that aluminum or iron phosphate precipitation captures orthophosphate. However, the difference in the average concentration of particulate orthophosphate at Chem-P compared with AS and EBPR was not as high as expected. Figure 3A shows that a significant portion of the phosphorus was present as condensed polyphosphates in Chem-P solids. The two Chem-P plants consist of three anoxic completely mixed reactors followed by oxidation ditches. It is possible that some fraction of these anoxic reactors operate under anaerobic (absence of oxygen and nitrate) instead of anoxic (absence of oxygen only) conditions, which could explain the significant quantities of polyphosphates observed in Fig. 3A. There are no anaerobic digesters in the chemical removal treatment plants sampled; therefore, it cannot be determined if the condensed polyphosphates in the Chem-P plants is PAO accumulated or another species of condensed polyphosphate.

EBPR solids contain significantly greater concentrations of polyphosphate than AS solids $(p=0.05)$ and, as a result, the dissolved orthophosphate concentration increases significantly for EBPR solids $(p<0.01)$ after digestion, but it remains approximately the same for the conventional AS plants $(p=0.9)$. This means that technologies that target dissolved orthophosphate for recovery would have similar mass recovery with undigested or with digested solids at conventional AS plants.

\section{Relating phosphorus speciation with phosphorus recovery}

Using the biosolid phosphorus speciation data collected in this study and the phosphorus recovery efficiencies reported for the AIRPREX ${ }^{\mathrm{TM}}$, Stuttgart process, and KREPRO technologies (Table 1), it is possible to estimate the phosphorus recovery potentially achievable for each type of wastewater solids examined in this study. AIRPREX ${ }^{\mathrm{TM}}$ is a struvite precipitation process that utilizes $\mathrm{pH}$ adjustment and $\mathrm{Mg}$ addition to promote precipitation. Stumpf et al. (2009) and Nieminen (2010) reported 90-98\% P recovery using the AIRPREX ${ }^{\mathrm{TM}}$ technology. Thus, for our calculations, it was assumed that the AIRPREX $^{\mathrm{TM}}$ technology would recover $90 \%$ of dissolved orthophosphate species (target species for AIRPREX ${ }^{\mathrm{TM}}$ ) present in each of the sampled solids. No other species of phosphorus is expected to be recovered by the AIRPREX ${ }^{\mathrm{TM}}$ technology. To obtain an estimate of the potential recovery, the possible recovery from the target species was multiplied by the concentration of the target species within the solids' type of interest.

As shown in Table 2, it is estimated that only 5\% of the total phosphorus present in the undigested EBPR solids can be recovered through the AIRPREX ${ }^{\mathrm{TM}}$ technology as opposed to $15 \%$ of the total phosphorus present in the digested EBPR solids. In contrast, using undigested conventional AS (AS9.5\% of TP) appears to have a greater recovery of phosphorus through the AIRPREX ${ }^{\mathrm{TM}}$ technology compared with using digested AS (7.8\% of TP). The explanation for increased recovery from conventional AS processes is the high fraction of the $\mathrm{P}$ in the orthophosphate particulate phase. Although some organic phosphorus appears to convert into orthophosphate after anaerobic digestion, the majority of orthophosphates are present in the particulate phase, which cannot be recovered through the AIRPREX ${ }^{\mathrm{TM}}$ technology (Fig. 3). The solids from chemical phosphorus removal have very low predicted recovery through the AIRPREX ${ }^{\mathrm{TM}}$ technology, which is expected since iron phosphate solids are stable at neutral $\mathrm{pH}$.

The Stuttgart recovery technology consists of lowering the $\mathrm{pH}$ of the biosolids to 2 to dissolve phosphorus bound to calcium, magnesium, aluminum, and iron (Güney et al.,

Table 2. Predicted Phosphorus Recovery and N:P $\mathrm{P}_{5}$ Ratios in the Wastewater Solids Before and After Treatment with the AIRPREX, Stuttgart, and KREPRO Phosphorus Recovery Technologies

\begin{tabular}{|c|c|c|c|c|c|}
\hline & \multicolumn{2}{|c|}{$A S$} & \multicolumn{2}{|c|}{$E B P R$} & \multirow{2}{*}{$\begin{array}{c}\text { Chem } \\
\begin{array}{c}\text { Undigested } \\
\text { solids }\end{array}\end{array}$} \\
\hline & $\begin{array}{l}\text { Undigested } \\
\quad \text { solids }\end{array}$ & $\begin{array}{l}\text { Digested } \\
\text { solids }\end{array}$ & $\begin{array}{l}\text { Undigested } \\
\quad \text { solids }\end{array}$ & $\begin{array}{l}\text { Digested } \\
\text { solids }\end{array}$ & \\
\hline \multicolumn{6}{|l|}{ AIRPREX (Struvite) } \\
\hline Predicted TP recovered $(\%)$ & $9.5 \pm 4.6$ & $7.8 \pm 5.3$ & $5.1 \pm 2.6$ & $15 \pm 2.4$ & $2.0 \pm 1.6$ \\
\hline $\mathrm{Kg}$ of $\mathrm{P}$ recovered per metric ton of dry solids & $1.3 \pm 0.6$ & $1.2 \pm 0.1$ & $1.0 \pm 0.6$ & $4.3 \pm 0.2$ & $0.5 \pm 0.5$ \\
\hline $\mathrm{N} / \mathrm{P}_{2} \mathrm{O}_{5}$ ratio before & $1.5 \pm 0.2$ & $1.3 \pm 0.2$ & $0.86 \pm 0.1$ & $0.70 \pm 0.1$ & $1.7 \pm 0.2$ \\
\hline $\mathrm{N} / \mathrm{P}_{2} \mathrm{O}_{5}$ ratio after & $1.6 \pm 0.1$ & $1.4 \pm 0.1$ & $0.90 \pm 0.02$ & $0.79 \pm 0.02$ & $1.7 \pm 0.01$ \\
\hline Is $\mathrm{N}: \mathrm{P}_{2} \mathrm{O}_{5}$ increase significant? ( $t$-test) & $\mathrm{No} / p=0.1$ & $\mathrm{No} / p=0.2$ & $\mathrm{No} / p=0.36$ & $\mathrm{No} / p=0.2$ & $\mathrm{No} / p=1$ \\
\hline \multicolumn{6}{|l|}{ Stuttgart Process (Struvite) } \\
\hline Predicted TP recovered $(\%)$ & $31 \pm 11$ & $50 \pm 20$ & $24 \pm 14.5$ & $69 \pm 11$ & $19 \pm 8.8$ \\
\hline $\mathrm{kg}$ of $\mathrm{P}$ recovered per metric ton of dry solids & $4.5 \pm 2.0$ & $8.8 \pm 6.3$ & $4.6 \pm 3.1$ & $19.7 \pm 1.1$ & $5.1 \pm 2.0$ \\
\hline $\mathrm{N} / \mathrm{P}_{2} \mathrm{O}_{5}$ ratio before & $1.5 \pm 0.2$ & $1.3 \pm 0.2$ & $0.86 \pm 0.1$ & $0.70 \pm 0.1$ & $1.7 \pm 0.2$ \\
\hline $\mathrm{N} / \mathrm{P}_{2} \mathrm{O}_{5}$ ratio after & $2.1 \pm 0.3$ & $3.3 \pm 3.1$ & $1.1 \pm 0.2$ & $2.0 \pm 0.7$ & $2.1 \pm 0.2$ \\
\hline Is $\mathrm{N}: \mathrm{P}_{2} \mathrm{O}_{5}$ increase significant? ( $t$-test) & Yes $/ p<0.01$ & $\mathrm{No} / p=0.1$ & Yes $/ p=0.03$ & Yes $/ p=0.03$ & Yes $/ p<0$ \\
\hline \multicolumn{6}{|l|}{ KREPRO (ferric phosphate) } \\
\hline Predicted TP recovered (\%) & $55 \pm 12$ & $61 \pm 18$ & $62 \pm 7.4$ & $81 \pm 8$ & $72 \pm 18$ \\
\hline $\mathrm{kg}$ of $\mathrm{P}$ recovered per metric ton of dry & $8.4 \pm 4.5$ & $11 \pm 7.2$ & $12 \pm 3.5$ & $23 \pm 2.0$ & $21 \pm 5.8$ \\
\hline $\mathrm{N} / \mathrm{P}_{2} \mathrm{O}_{5}$ ratio before & $1.5 \pm 0.2$ & $1.3 \pm 0.2$ & $0.86 \pm 0.1$ & $0.70 \pm 0.1$ & $1.7 \pm 0.2$ \\
\hline $\mathrm{N} / \mathrm{P}_{2} \mathrm{O}_{5}$ ratio after & $3.7 \pm 1.7$ & $4.1 \pm 2.3$ & $2.3 \pm 0.5$ & $4.3 \pm 2.3$ & $8.8 \pm 5.7$ \\
\hline Is $\mathrm{N}: \mathrm{P}_{2} \mathrm{O}_{5}$ increase & Yes/p $<0.01$ & Yes $/ p=0.04$ & Yes $/ p<0.01$ & Yes $/ p=0.05$ & Yes $/ p<0$ \\
\hline
\end{tabular}

Bold values indicate the $\mathrm{N}: \mathrm{P}_{2} \mathrm{O}_{5}$ increase is statistically significant. 
2008). The solids are then dewatered and the liquid portion (sidestream) is dosed with the complexing agent citric acid to prevent precipitation of phosphorus with aluminum and iron. Magnesium hydroxide and sodium hydroxide are then added for struvite precipitation (Antakyali et al., 2013). It has been demonstrated that $98 \%$ of the phosphorus dissolved (at $\mathrm{pH} 2$ ) can be recovered as struvite through the Stuttgart process (Güney et al., 2008; Antakyali et al., 2013). This phosphorus recovery technology is similar to our method for determination of total orthophosphate (dissolved+particulate orthophosphate). Thus, we assumed that $98 \%$ of the total orthophosphate species (target species for Stuttgart) measured in each of the sampled solids can be recovered through the Stuttgart process. This estimate was used to calculate a potential recovery as described previously for the AIRPREX ${ }^{\mathrm{TM}}$ process.

Data presented in Table 2 show that the Stuttgart process significantly improves the predicted potential for $\mathrm{P}$ recovery from all types of solids compared with the recovery with the AIRPREX $^{\mathrm{TM}}$ technology. With the Stuttgart recovery technology, the predicted recovery from digested AS solids is now greater than the recovery from undigested biosolids because this technology captures the particulate orthophosphate formed during anaerobic digestion. For the solids from chemical phosphorus removal, there is also improvement when compared with the performance with the AIRPREX ${ }^{\mathrm{TM}}$ technology since the orthophosphate that was bound to aluminum and iron during chemically enhanced phosphorus removal is released at $\mathrm{pH} 2$.

Finally, the KREPRO technology consists of acidification of solids, then heating to just over $100^{\circ} \mathrm{C}$ at a pressure of 3.6 bar for $30 \mathrm{~min}$ to hydrolyze the condensed polyphosphates into orthophosphates (Hansen et al., 2000). Subsequently, the solids are cooled and dewatered. The sidestream from the dewatering process (liquid portion) is utilized for ferric phosphate precipitation at $\mathrm{pH} 2.8$. Hansen et al. (2000) estimated that $90 \%$ of the phosphorus dissolved in the dewatering supernatant can be recovered by ferric phosphate precipitation. This recovery technology is similar to our method for determination of acid-hydrolyzable phosphorus (Orthophosphates+Condensed Polyphosphates) described previously. Moreover, the phosphorus speciation data col- lected in the current study indicate that acid-hydrolyzable phosphorus accounts for $60-80 \%$ of the total phosphorus before digestion and between $78 \%$ and $89 \%$ of the total phosphorus after digestion (Fig. 3). This range falls within the recovery reported by Karlsson and Kemira (2001). Therefore, it was assumed that $90 \%$ of the acid-hydrolyzable phosphorus (target species for KREPRO) present in the sampled solids can be recovered through the KREPRO process. The assumption was then used to calculate the potential for phosphorus recovery as described previously.

Using the KREPRO technology, over $50 \%$ of the phosphorus could be recovered for all types of solids (Table 2). For EBPR, there is greater recovery with digested solids than with undigested solids since part of the organic phosphorus degrades during anaerobic digestion and forms orthophosphate. For the same reason, digested AS solids achieve greater recovery than undigested AS solids with the KREPRO technology. It is predicted that over $70 \%$ of the total phosphorus present can be recovered from Chem-P WWTPs solids utilizing the KREPRO technology. This technology takes advantage of the phosphorus bound as condensed polyphosphate in the solids, which are a significant fraction of the phosphorus in solids from sampled plants with chemical phosphorus removal.

A comparison of the recovered phosphorus calculated through phosphorus speciation (This study) and the total phosphorus recovery reported in other published studies is summarized in Table 3. This comparison shows consistency between estimating phosphorus recovery potential from our phosphorus speciation data to that obtained from other independent studies.

\section{Predicting $\mathrm{N}: \mathrm{P}_{2} \mathrm{O}_{5}$ ratio changes}

To calculate the $\mathrm{N}: \mathrm{P}_{2} \mathrm{O}_{5}$ ratios of the sampled wastewater biosolids before any phosphorus recovery, the total nitrogen concentrations were obtained from the records of three of the treatment plants studied. The records provided by the plant staff contained years worth of nitrogen measurements and it was preferred over sampling done by this study as it was considered to be more robust. For assurance, the calculated

Table 3. Comparison of Recovery Potentials Used in Based on the Phosphorus Speciation With the Recovery Potentials Published in Other Studies

\begin{tabular}{lclr}
\hline Recovery technology & Recovery $(\%$ of TP) & \multicolumn{1}{c}{ References } & Type of solids \\
\hline AIRPREX & 25 & Amann et al. $(2018)$ & EBPR \\
AIRPREX & 25 & Jossa and Remy (2015) & EBPR \\
AIRPREX $^{\mathrm{TM}}$ & 7 & This study & AS \\
AIRPREX & 8 & This study & Chem-P \\
AIRPREX & 2 & This study & EBPR \\
KREPRO & 2 & Lundin et al. $(2004)$ & EBPR \\
KREPRO & 15 & This study & AS \\
KREPRO & 80 & This study & Chem-P \\
KREPRO & 61 & This study & EBPR \\
Stuttgart & 72 & Amann et al. $(2018)$ & EBPR \\
Stuttgart & 81 & Jossa and Remy $(2015)$ & Chem-P \\
Stuttgart & $35-55$ & This study & AS \\
Stuttgart & 45 & This study & ChemP \\
Stuttgart & 50 & This study & EBPR \\
\hline
\end{tabular}

AS, activated sludge. 
$\mathrm{N}: \mathrm{P}_{2} \mathrm{O}_{5}$ ratios were compared against the pertinent published literature and correlated closely with studies by Maguire $\mathrm{et} \mathrm{al}$. (2001), Penn and Sims (2002), Chinault and O'Connor (2008), and many others (Supplementary Table S4).

To calculate the $\mathrm{N}: \mathrm{P}_{2} \mathrm{O}_{5}$ ratios after phosphorus recovery, the moles of phosphorus and nitrogen estimated to be recovered through each of the studied technologies were subtracted from the prerecovery phosphorus and nitrogen concentrations. Then, a new $\mathrm{N}: \mathrm{P}_{2} \mathrm{O}_{5}$ ratio was obtained (Table 2). We limited our discussion to the statistical significance of differences in ratios and not the absolute $\mathrm{N}: \mathrm{P}_{2} \mathrm{O}_{5}$ values. The significance of the increase in $\mathrm{N}: \mathrm{P}_{2} \mathrm{O}_{5}$ after phosphorus recovery was tested using a one-sided Student's $t$-test with a critical $\alpha$ of 0.05 .

Recovery through AIRPREX ${ }^{\mathrm{TM}}$ technology does not increase the $\mathrm{N}: \mathrm{P}_{2} \mathrm{O}_{5}$ ratio significantly in the spent solids. Struvite also removes nitrogen and thus prevents the $\mathrm{N}: \mathrm{P}_{2} \mathrm{O}_{5}$ ratios from increasing significantly with the AIRPREX ${ }^{\mathrm{TM}}$ technology. Therefore, recovery through AIRPREX ${ }^{\mathrm{TM}}$ would not alleviate the issues of overaccumulating phosphorus at land application fields.

The $\mathrm{N}: \mathrm{P}_{2} \mathrm{O}_{5}$ ratios increase significantly after the recovery of phosphorus with the Stuttgart technology for all types of wastewater solids, except digested AS solids. The variability on the AS data yielded a high standard deviation and a low confidence of $\mathrm{N}: \mathrm{P}_{2} \mathrm{O}_{5}$ increase $(p=0.1)$.

With the KREPRO technology, the predicted $\mathrm{N}: \mathrm{P}_{2} \mathrm{O}_{5}$ ratios of the spent solids increase significantly regardless of the phosphorus removal processes employed at the wastewater treatment plant. These results are important if the spent solids are to be utilized for farmland application. However, additional research is required to determine the effects that spent solids generated from the KREPRO phosphorus recovery technology will have on crops following land application of the treated solids.

\section{Effect of thickening on phosphorus speciation}

Apart from examining the broad picture of predicting phosphorus recovery and improvements to $\mathrm{N}: \mathrm{P}_{2} \mathrm{O}_{5}$ ratios, this study also investigated the effects of solid treatment processes (e.g., Thickening and Digestion) on the phosphorus speciation.

Experiments by Marti et al. (2008b) and Pastor et al. (2008) demonstrated that during gravity thickening of EBPR sludge, orthophosphate can be released due to PAO-polyphosphate hydrolysis. Conventional AS does not promote microorganism overaccumulation of PAO-polyphosphates, however, it was hypothesized that there is some PAO-polyphosphate presence within the wastewater solids and under the anaerobic conditions developed within the thickeners there could be a detectable release. Thus, the hypothesis evaluated in this work was that the thickening process promotes the hydrolysis of polyphosphates within conventional AS. To investigate this hypothesis, the speciation of phosphorus before and after gravity thickening was determined and compared with the phosphorus speciation in EBPR solids and AS solids thickened by DAF and gravity belt thickeners (GBTs). DAF thickeners utilize high-pressure air bubbles to remove particles for suspension (Turovskiı and Mathai, 2006) and in doing so maintain aerobic conditions. Thus, no hydrolysis of PAOpolyphosphate is expected in these thickeners allowing this system to serve as a control. GBTs have a higher solid loading rate than gravity thickeners, consequently, solids have less opportunity to become anaerobic and hydrolysis is not expected to occur. The storage tank in the EBPR2 wastewater treatment plant was used as a proxy for gravity thickening, since it is estimated that sludge remains inside the steel tank for about a day. These conditions are suitable to develop anaerobic conditions and hydrolysis is expected to occur to some extent.

Figure 4A summarizes the dissolved orthophosphate concentrations pre- and post-thickening at each of the five conventional AS treatment plants investigated in this study normalized per gram of dry solids. In contrast, PAOpolyphosphate hydrolysis was not expected across the DAF thickener as it should be an aerobic system. Indeed, no apparent difference in condensed polyphosphate concentrations was observed; however, total orthophosphate appears to increase while organic phosphorus may have decreased. This is consistent with potential biochemical oxidation of the organic matter within the sludge. Experiments by Butler et al. (1997) showed a significant reduction of chemical and biological oxygen demand across DAF thickeners. These results cannot be statistically validated; regardless, the results do suggest that liquid recycle from DAF thickeners is not an optimal method for achieving phosphorus recovery by dissolved orthophosphate precipitation.

The EBPR2 WAS stored in the steel tank released about $3.9 \mathrm{mg} / \mathrm{g}(p=0.04)$ (Supplementary Table S5) of orthophosphate as shown in Fig. 4A. This result is on the same order of magnitude as that reported by Pastor et al. (2008) who measured a release of at least $7.8 \mathrm{mg} / \mathrm{g}$ of phosphorus during gravity thickening. In addition, a decrease in condensed polyphosphates was observed for EBPR2, however, the results were not statistically significant given the variability observed. To confirm if PAO-hydrolysis occurred in EBPR2's storage tank, the magnesium and potassium concentrations were evaluated. Magnesium and potassium are counter ions for PAO-polyphosphate hydrolysis. This means that these ions are released from phosphorus accumulating bacteria to the solution together with orthophosphate during hydrolysis (Jardin and Popel, 1994; Marti et al., 2008b; Pastor et al., 2008). Previous studies (Pastor et al., 2008) have reported potassium releases between 3.9 and $134 \mathrm{mg} / \mathrm{L}$ and magnesium releases between 3.1 and $107 \mathrm{mg} / \mathrm{L}$ during anaerobic PAO-polyphosphate hydrolysis. In the current study, the dissolved magnesium and potassium concentrations increased by 23 and $40 \mathrm{mg} / \mathrm{L}$, respectively, after storage, which supports operative PAO-polyphosphate hydrolysis reactions at EBPR2 as expected.

Gravity thickeners that only treat WAS (AS1 and AS3) yielded increased dissolved orthophosphate concentrations (Fig. 4A). For the AS4 gravity thickener, the concentration of dissolved orthophosphate remains the same after thickening (Fig. 4A).

The particulate orthophosphate concentrations (Fig. 4B) are the same before and after thickening for all treatment plants, except for AS4, where it increases significantly $(p=0.01)$. At AS4, both primary and secondary sludge are mixed before gravity thickening. Experiments by Pastor $\mathrm{et} \mathrm{al}$. (2008) suggest that the volatile fatty acids in primary sludge promotes hydrolysis of polyphosphates, and in turn increase the potential for phosphorus precipitation due to the higher concentrations of dissolved calcium in primary sludge (e.g., in AS4, $\mathrm{Ca}^{2+}$ was measured to be $44 \pm 4 \mathrm{mg} / \mathrm{L}$ in the primary sludge and $19 \pm 5 \mathrm{mg} / \mathrm{L}$ in the secondary sludge). Effectively, 
FIG. 4. Phosphorus speciation pre- and post-thickening at the different treatment plants sampled. (A) Dissolved orthophosphate, (B) particulate orthophosphate, (C) total condensed polyphosphate, and (D) total organic phosphates. Concentrations expressed as $\mathrm{mg}$ $\mathrm{P}$ per $\mathrm{g}$ of dry solids. AS, activated sludge.
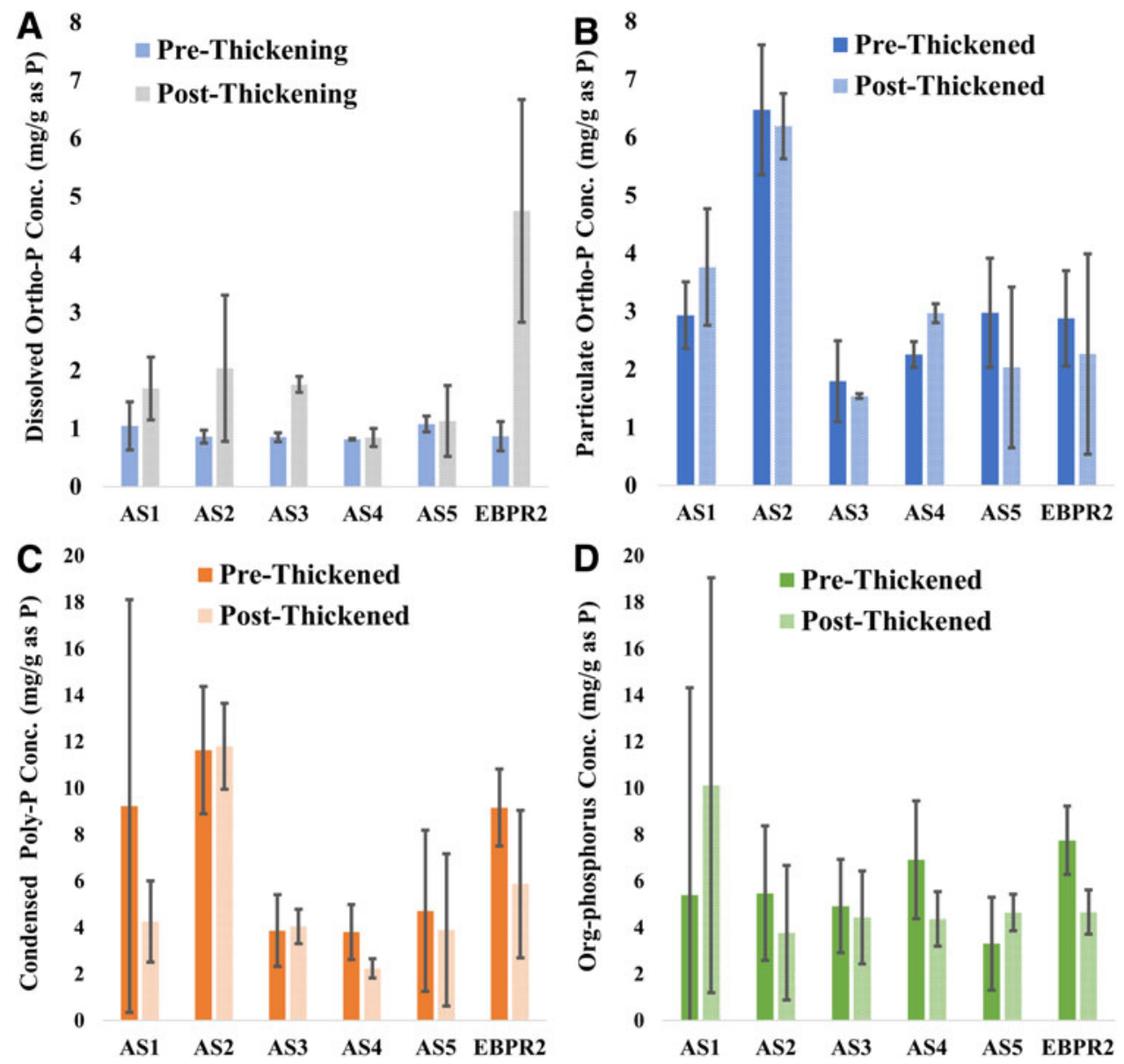

in Fig. 4C it appears that for AS4 there is a decrease in condensed polyphosphate similar to the decrease in EBPR2. This could suggest that hydrolysis of PAO-polyphosphates occurs in gravity thickener AS4 and that the orthophosphate formed precipitates and contributes to the observed increase in particulate orthophosphate in thickener AS4. In thickener $\mathrm{AS} 1$, there is also a decrease in average condensed polyphosphate concentration, but the standard deviation before thickening is too large to draw this conclusion.

To further examine the possible link between anaerobic conditions and differences in phosphorus speciation in gravity thickeners, it is necessary to consider variations in hydraulic residence times (HRTs) (Table 4). AS4 and AS1 have the longest HRTs. Thus, we can hypothesize that longer HRTs in gravity thickeners treating conventional AS favor the devel-

Table 4. Hydraulic Residence Time FOR THE GRAVITY THICKENERS SAMPLED

\begin{tabular}{lc}
\hline & HRT (days) \\
\hline AS1 & 1 \\
AS2 & 0.6 \\
AS3 & 0.3 \\
AS4 & 0.9 \\
AS5 & Minutes \\
EBRP2 & $1^{\mathrm{a}}$ \\
\hline
\end{tabular}

${ }^{\mathrm{a}}$ Estimate by operators.

HRT, hydraulic residence time. opment of anaerobic conditions that promote reactions that decrease condensed polyphosphate concentrations.

Finally, there is an observable decrease in organic phosphorus for AS2, AS4, and EBPR2; but, only in EBPR2 was there a statistically significant reduction $(p=0.02)$ (Supplementary Table S2) after thickening. This would indicate some degradation of the organic matter inside the steel storage tank and possibly the AS thickeners.

While it was apparent that EBPR thickeners are a good source of dissolved orthophosphate for P recovery, the AS thickeners have potential for some hydrolysis of condensed polyphosphates. As expected, for the GBT at AS5 there were no significant increases or decreases for any of the phosphorus species.

\section{Effect of anaerobic digestion on phosphorus speciation}

Many researchers have reported increases in dissolved orthophosphate in EBPR sludge after anaerobic digestion (Takiguchi et al., 2004; Marti et al., 2008b; Pastor et al., 2008). The increase in dissolved orthophosphate is due to polyphosphate hydrolysis from phosphate accumulating organisms in the solids (Hrenovic et al., 2009; Yuan et al., 2012; Kodera et al., 2013). Figure 5 provides a comparison of dissolved (Fig. 5A) and particulate (Fig. 5B) orthophosphate levels in samples from EBPR1 and each of the conventional treatment plant anaerobic digestion systems normalized by the grams of dry solids fed to their corresponding digester. As expected, there was a doubling of dissolved orthophosphate and a 

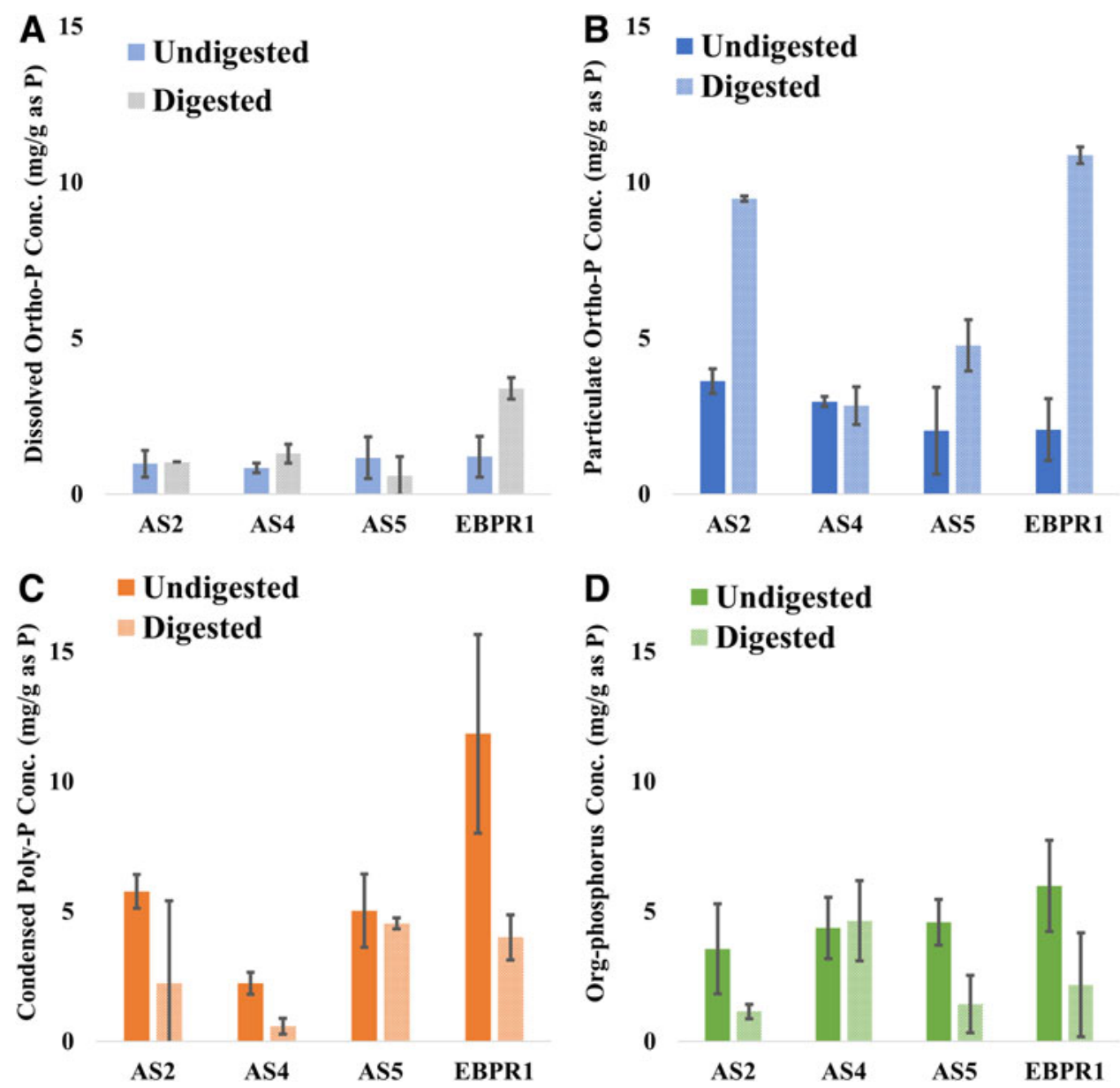

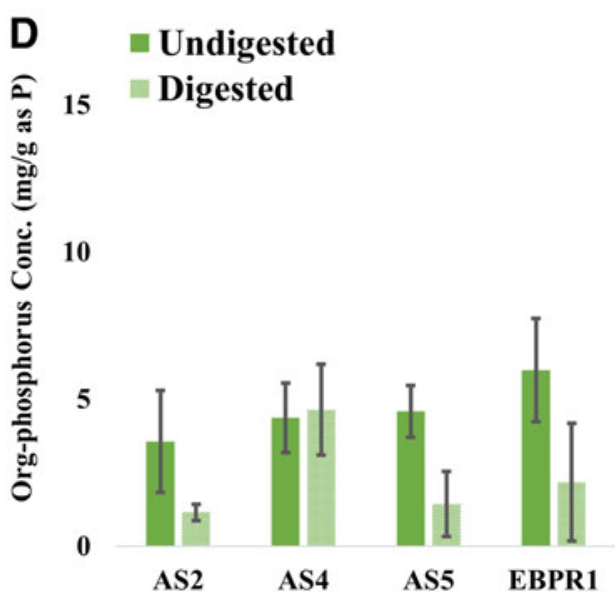

FIG. 5. Phosphorus speciation before and after anaerobic digestion at the different treatment plants sampled. (A) Dissolved orthophosphate, (B) particulate orthophosphate, $(\mathbf{C})$ total condensed polyphosphate, and (D) organic phosphorus. Concentrations expressed as mg P per g of dry solids fed to anaerobic digester.
$5 \times$ increase in particulate orthophosphate for EPBR1 following digestion. The dissolved orthophosphate results match those of Takiguchi et al. (2004) who reported an almost doubling of the concentration of soluble phosphorus after mesophilic digestion of EBPR biosolids. Pastor et al. (2008) and Marti et al. (2008b) and Marti et al. (2010) also reported an increase of slightly over $50 \%$ in dissolved orthophosphate after digestion provided that WAS and primary sludge do not comingle before gravity thickening, as is the case for EBPR1. In addition, samples from EBPR1 showed a decrease in both the condensed polyphosphate concentration $(p=0.03)$ and in the organic phosphorus concentration after anaerobic digestion $(p=0.03)$.

Comparison of the pre- and postdigestion orthophosphate concentrations showed varying trends among the three conventional activated sludge (AS) plants. Only in plant AS4 was there a significant increase $(0.8-1.3 \mathrm{mg} / \mathrm{g})$ in the average dissolved orthophosphate concentration (Fig. 5A) following anaerobic digestion $(p=0.05)$. In contrast, increases in particulate orthophosphate pre- and postdigestion were observed for all digesters, except for AS4. As discussed previously, AS4 mixes primary and secondary sludge before thickening, which is believed to promote precipitation of phosphorus with calcium inside the thickener. The loss of calcium during thickening could explain the lack of particulate phosphorus increase in the AS4 digester. In contrast, AS2 and AS5 mix primary and secondary sludge before digestion and thus allow for precipitation of orthophosphate inside the digester. Indeed, the concentration of calcium decreased by near $50 \%$ after digestion for AS2 and AS5. These results suggest that higher quantities of phosphorus could be recovered by targeting total orthophosphates in conventional AS plants.

Since dissolved orthophosphate concentrations remain relatively constant before and after digestion in the AS plants, the increases in particulate orthophosphate could be the result of hydrolysis of condensed polyphosphates or degradation of organic phosphorus into dissolved orthophosphate and subsequent precipitation to the particulate phase. Figure $4 \mathrm{C}$ shows a decrease in condensed polyphosphate concentrations after anaerobic digestion at AS4 $(p=0.01)$. For AS2 and AS5 the condensed polyphosphate concentration decrease cannot be statistically confirmed. Organic phosphorus concentrations on the other hand, showed a significant decrease for AS2 and AS5. These results suggest that for AS2 and AS5 the increase in orthophosphate concentration is mainly due to organic phosphorus degradation, and for AS4 the increase is mainly due to condensed polyphosphate hydrolysis.

To determine if PAO polyphosphate hydrolysis occurs in AS4, the concentration of dissolved magnesium and potassium before and after digestion was measured (Supplementary Fig. S1). The data (Supplementary Fig. S1) show that for anaerobic digestion, where condensed polyphosphate decreases were statistically confirmed, (AS4 and EBPR2) the dissolved magnesium and potassium concentration increased after anaerobic digestion which is indicative of PAO polyphosphate hydrolysis. The magnesium and potassium concentrations for AS2 only increased slightly, on the other hand, for AS5 only the potassium concentration increased slightly while the magnesium concentration decreased. The slight increase in 
potassium and magnesium concentrations for AS2 and potassium for AS5 might be the result of degradation of organic matter rather than PAO polyphosphate hydrolysis.

To confirm the hydrolysis of PAO polyphosphates in AS4, the molar ratios of $\mathrm{Mg}$-increase/PolyP-decrease $(\Delta \mathrm{Mg} / \Delta \mathrm{PP})$ were calculated and compared with EBPR1. The $\Delta \mathrm{Mg} / \Delta \mathrm{PP}$ for the EBPR1 plant was 0.23 and this closely aligns with reported ratios of $\mathrm{Mg}$-release/ortho-P-release (Jardin and Popel, 1994; Pastor et al., 2008). The $\Delta \mathrm{Mg} / \Delta \mathrm{PP}$ for AS4 was calculated to be higher at 0.7 . This may suggest that the increase in magnesium concentration is not the result of PAO polyphosphate hydrolysis but possibly a result of hydrolysis of other species of condensed polyphosphates. Further study is required to distinguish between PAO polyphosphates and other condensed polyphosphates.

The literature addressing phosphorus recovery technologies typically focus on recovery of dissolved orthophosphate after anaerobic digestion (Shimamura et al., 2003, 2008; Rittmann et al., 2011; Sartorius et al., 2012; Mehta and Batstone, 2013). However, the present results suggest that when using phosphorus recovery technologies that target dissolved orthophosphate, there is no difference in using AS undigested or digested solids. These results also suggest that to recover greater quantities of phosphorus from anaerobically digested conventional AS biosolids, the use of a technology that targets particulate orthophosphate is most appropriate than technologies that target only dissolved species.

\section{Conclusions}

This study addressed phosphorus recovery from wastewater solids for a range of treatment configurations, use of different technologies, and suitability for land application.

The study concluded that the type of wastewater treatment process has a significant impact on the selection of solid feed for phosphorus recovery. Also, phosphorus speciation should play a greater role in the selection of technologies for phosphorus recovery. Finally, the results suggest that only enhanced technologies that target particulate phosphorus phases have the potential to improve $\mathrm{N}: \mathrm{P}_{2} \mathrm{O}_{5}$ ratios of the spent solids.

Future work is required to further evaluate the benefits of implementing more advanced $\mathrm{P}$ recovery technologies.

\section{Acknowledgments}

The authors would like to acknowledge the support and input of Raj Bhattarai of the WEF Board of Trustees, as well as the engineers and operators of the contributing wastewater treatment facilities.

\section{Author Disclosure Statement}

No competing financial interests exist.

\section{Funding Information}

No funding was received for this article.

\section{Supplementary Material}

Supplementary Figure S1

Supplementary Table S1

Supplementary Table S2

Supplementary Table S3

Supplementary Table S4
Supplementary Table S5 Supplementary Table S6 Supplementary Table S7 Supplementary Table S8

\section{References}

Amann, A., Zoboli, O., Krampe, J., Rechberger, H., Zessner, M., and Egle, L. (2018). Environmental impacts of phosphorus recovery from municipal wastewater. Resour. Conserv. Recy. 130, 127.

American Public Health Association (APHA). (2012). Standard Methods for the Examination of Water and Wastewater, 22nd ed. Washington, DC: American Public Health Association, American Water Works Association, and Water Environment Federation.

Antakyali, D., Meyer, C., Preyl, V., Maier, W., and Steimetz, H. (2013). Large-scale application of nutrient recovery from digested sludge as struvite. Water Pract. Technol. 8, 256.

Barnard, J. (1984). Activated primary tanks for phosphate removal. Water SA 10, 121.

Brunner, P.H. (2010). Substance flow analysis as a decision support tool for phosphorus management. J. Ind. Ecol. 14, 870.

Butler, R.C., Finger, R.E., Pitts, J.F., and Strutynski, B. (1997). Advantages of cothickening primary and secondary sludges in dissolved air flotation thickeners. Water Environ. Res. 69, 311.

Chinault, S.L., and O'Connor, G.A. (2008). Phosphorus release from a biosolids-amended sandy spodosol. J. Environ. Qual. 37, 937.

Coats, E.R., Watkins, D.L., and Kranenburg, D. (2011). A comparative environmental life-cycle analysis for removing phosphorus from wastewater: Biological versus physical/ chemical processes. Water Environ. Res. 83, 750.

Cordell, D., Drangert, J.-O., and White, S. (2009). The story of phosphorus: Global food security and food for thought. Global Environ. Chang. 19, 292.

Cullen, N., Baur, R., and Schauer, P. (2013). Three years of operation of North America's first nutrient recovery facility. Water Sci. Technol. 68, 763.

Danesh, P., Hong, S.M., Moon, K.W., and Park, J. K. (2008). Phosphorus and heavy metal extraction from wastewater treatment plant sludges using microwaves for generation of exceptional quality biosolids. Water Environ. Res. 80, 784.

Dueñas, J.F., Alonso, J.R., Rey, À.F., and Ferrer, A.S. (2003). Characterisation of phosphorous forms in wastewater treatment plants. J. Hazard. Mater. 97, 193.

Environmental Protection Agency (EPA). (1996). Method 6010B: Inductively coupled plasma-atomic emission spectrometry. Rev. 2. Washington, DC pp. 1-25.

Environmental Protection Agency (EPA). (2016). Action towards limiting total nitrogen, total phosphorus, and total inorganic nitrogen loads from NPDES-permitted facilities. https://19January2017.epa.gov/nutrient-policy-data/actiontowards-Limiting-total-nitrogen-total-phosphorus-and-totalinorganic.html Accessed on May 11, 2016.

George, T.S., Hinsinger, P., and Turner, B.L. (2016). Phosphorus in soils and plants-Facing phosphorus scarcity. Plant Soil 401, 1.

Greenfield, S., and Clift, M. (1975). Analytical Chemistry of the Condensed Phosphates, 1st ed. R. Belcher and H. Freiser, Eds. Pergamon Press, Oxford.

Güney, K., Weidelener, A., and Krampe, J. (2008). Phosphorus recovery from digested sewage sludge as MAP by the help of metal ion separation. Water Res. 42, 4692.

Hansen, B., Karlsson, I., Cassidy, S., and Pettersson, L. (2000). Operational experiences from a sludge recovery plant. Water Sci. Technol. 41, 23. 
Hrenovic, J., Ivankovic, T., and Tibljas, D. (2009). The effect of mineral carrier composition on phosphate-accumulating bacteria immobilization. J. Hazard. Mater. 166, 1377.

Hultman, B. (1999). Trends in Swedish sludge handling. Proceedings of Polish-Swedish seminar, Royal institute of technology (KTH). pp. 13-22. Stockholm, Sweden.

Jardin, N., and Popel, J. (1994). Phosphate release of sludge from enhanced biological p-removal during digestion. Water Sci. Technol. 30, 281.

Jossa, P., and Remy, C. (2015). Sustainable sewage sludge management fostering phosphorus recovery and energy efficiency: Life cycle assessment of selected processes for $P$ recovery from sewage sludge, sludge liquor, or ash (D 9.2). www.kompetenz-wasser.de/wp-content/uploads/2017/05/p-rexdp_2_Environmental_impact_assessmental_lca_remy-2015.pdf Last accessed on February 21, 2020.

Karlsson, I., and Kemira, K. (2001). Full scale plant recovering iron phosphate from sewage at Helsingborg Sweden. Mercury 1, 2.

Kodera, H., Hatamoto, M., Abe, K., Kindaichi, T., Ozaki, N., and Ohashi, A. (2013). Phosphate recovery as concentrated solution from treated wastewater by a PAO-enriched biofilm reactor. Water Res. 47, 2025.

Korboulewsky, N., Dupouyet, S., and Bonin, G. (1989). Environmental risks of applying sewage sludge compost to vineyards: Carbon, heavy metals, nitrogen, and phosphorus accumulation. J. Environ. Qual. 31, 1522.

Kuroda, A., Takiguchi, N., Gotanda, T., and Nomura, K. (2002). A simple method to release polyphosphate from activated sludge for phosphorus reuse and recycling. Biotechnol. Bioeng. 78, 333.

Lawler, D.F., and Singer, P.C. (1984). Return flows from sludge treatment. J. Water Pollut. Control Fed. 56, 118.

Lundin, M., Olofsson, M., Pettersson, G.J., and Zetterlund, H. (2004). Environmental and economic assessment of sewage sludge handling options. Resour. Conserv. Recy. 41, 255.

Maguire, R.O., Sims, J.T., Dentel, S.K., Coale, F.J., and Mah, J.T. (2001). Relationship between biosolids treatment process and soil phosphorus availability. J. Environ. Qual. 30, 1023.

Marti, N., Ferrer, J., Seco, A., and Bouzas, A. (2008b). Optimisation of sludge line management to enhance phosphorus recovery in WWTP. Water Res. 42, 4609.

Marti, N., Pastor, L., Bouzas, A., Ferrer, J., and Seco, A. (2010). Phosphorus recovery by struvite crystallization in WWTPs: Influence of the sludge treatment line operation. Water Res. 44, 2371.

Mayer, B.K., Baker, L.A., Boyer, T.H., Drechsel, P., Gifford, M., Hanjra, M.A., Parameswaran, P., Stoltzfus, J., Westerhoff, P., and Rittmann, B.E. (2016). Total value of phosphorus recovery. Environ. Sci. Technol. 50, 6606.

Mehta, C.M., and Batstone, D.J. (2013). Nutrient solubilization and its availability following anaerobic digestion. Water Sci. Technol. 67, 756.

Münch, E.V., and Barr, K. (2001). Controlled struvite crystallisation for removing phosphorus from anaerobic digester sidestreams. Water Res. 35, 151.

Nieminen, J. (2010). Phosphorus Recovery and Recycling from Municipal Wastewater Sludge. Available at: http://civil.aalto.fi/ fi/midcom-serveattachmentguid-1e388d0812d4d8488d011e38 efe7b3ce80f1ef31ef3/nieminen2010.pdf Accessed on February $21,2020$.
Pastor, L., Marti, N., Bouzas, A, and Seco, A. (2008). Sewage sludge management for phosphorus recovery as struvite in EBPR wastewater treatment plants. Bioresour. Technol. 99, 4817.

Penn, C.J., and Sims, J.T. (2002). Phosphorus forms in biosolidsamended soils and losses in runoff: effects of wastewater treatment process. J. Environ. Qual. 31, 1349. DOI: 10.2134/ JC72002.1349.

Petzet, S., and Cornel, P. (2009). Phosphorus removal and recovery from sewage sludge as calcium phosphate by addition of calcium silicate hydrate compounds (CSH). In International Conference on Nutrient Recovery from Wastewater Streams, Vancouver, Canada.

Rittmann, B.E., Mayer, B., Westerhoff, P., and Edwards, M. (2011). Capturing the lost phosphorus. Chemosphere 84, 846.

Sartorius, C., Horn, J. Von, and Tettenborn, F. (2012). Phosphorus recovery from wastewater-Expert survey on present use and future potential. Water Environ. Res. 84, 313.

Sengupta, S., Nawaz, T., and Beaudry, J. (2015). Nitrogen and phosphorus recovery from wastewater. Curr. Pollut. Rep. 1, 155.

Shaw, A., Koch, D., Wirtel, S., and Britton, A. (2014). The multiple benefits of phosphorus recovery. In Proceedings of the Water Environment Federation. DOI: 10.1017/CBO978 1107415324.004, New Orleans, LA.

Shimamura, K., Homma, Y., Watanabe, A., and Tanaka, T. (2003). Research on MAP recovery conditions using a fluidizedbed crystallized phosphorous removal system. J. Water Environ. Technol. 1, 73.

Shimamura, K., Ishikawa, H., Mizuoka, A., and Hirasawa, I. (2008). Development of a process for the recovery of phosphorus resource from digested sludge by crystallization technology. Water Sci. Technol. 57, 451.

Stumpf, D., Heinzmann, B., Schwarz, R.J., Gnirss, R., and Kraume, M. (2009). Induced struvite precipitation in an airlift reactor for phosphorus recovery. In International Conference on Nutrient Recovery from Wastewater Streams. Vancouver, Canada.

Szpyrkowicz, L. (1995). Seasonal phosphorus removal in a Phostrip process-I. Two-years' plant performance. Water Res. 29, 2318.

Takiguchi, N., Kishino, M., Kuroda, A., Kato, J., and Ohtake, H. (2004). A laboratory-scale test of anaerobic digestion and methane production after phosphorus recovery from waste activated sludge. J. Biosci. Bioeng. 97, 365.

Tchobanoglous, G., Burton, F.L., and Stensel, H.D. (2004). Wastewater Engineering: Treatment and Reuse. Boston, MA: McGraw-Hill.

Turovskiiu, I.S., and Mathai, P.K. (2006). Wastewater Sludge Processing. Hoboken, NJ: Wiley-Interscience.

Withers, P.J.A., Elser, J.J., Hilton, J., and Ohtake, H. (2015). Green chemistry can help achieve planetary. Green Chem. 17, 2087.

Yuan, Z., Pratt, S., and Batstone, D.J. (2012). Phosphorus recovery from wastewater through microbial processes. Curr. Opin. Biotechnol. 23, 878.

Zeng, S., Yuan, X., Shi, X., and Qiu, Y. (2010). Effect of inoculum/substrate ratio on methane yield and orthophosphate release from anaerobic digestion of Microcystis spp. J. Hazard. Mater. 178, 89. 